\title{
Procesos de subjetivación de género en las trabajadoras de la minería del cobre en Chile. El caso de la División El Teniente
}

\author{
Raúl Troncoso del Río ${ }^{1}$
}

Fecha de recepción: 25 de noviembre de 2014

Fecha de aprobación: 5 de diciembre de 2014

\section{Resumen}

El mercado laboral en Chile ha tenido una creciente participación femenina, lo cual ha desdibujado los márgenes tradicionales de la división sexual del trabajo. Esto se evidencia con el emergente fenómeno de la incorporación de mujeres en las labores productivas de la minería del cobre. La empresa Codelco ha justificado esta extensión en su fuerza de trabajo a partir de los beneficios que reporta en la productividad y el clima laboral. Sin embargo, poco se ha dicho desde el punto de vista de los actores involucrados. De ahí que el presente artículo se ancle desde la sociología de la experiencia de François Dubet, con el objetivo de examinar, a través de los relatos de las trabajadoras de la División El Teniente, los procesos de subjetivación de género que se estructuran a partir de su experiencia laboral. Las claves que dan forma a dichos procesos están dadas por los dramas, desafíos, tensiones en su identidad y los juicios propios sobre su experiencia en la minería, que les lleva a configurar una emergente ruptura con el "Yo social" femenino, y asumir el deseo de ser autoras de sus vidas, a partir de un proyecto ético por la igualdad de género.

Palabras clave: Experiencia laboral, subjetivación de género, mujeres, minería.

\section{Gender subjectivity processes in women working in copper mining in Chile. The case of El Teniente division}

\begin{abstract}
The labor market in Chile has had a growing female participation, which has blurred the traditional margins of the gender division of labor. This is evidenced by the emerging phenomenon of incorporating women in copper
\end{abstract}

Sociólogo, Universidad Alberto Hurtado, Santiago de Chile. Ayudante de investigación del proyecto Semilla "Disposiciones y resistencias subjetivas a la participación sindical en mujeres de la gran minería del cobre en Chile", VRAUniversidad Diego Portales 2015-2016. Coordinador ejecutivo de proyecto Fondecyt Regular N¹131018, Universidad de Chile. rault90@gmail.com. 
mining productive work. Codelco company has justified this extension in its work force by the benefits it implies in productivity and working environment. However, little has been said from the point of view of actors involved. Hence this article is anchored in the sociology of the experience of François Dubet, in order to examine, through the stories of the women working at El Teniente division, the gender subjectivity processes structured from this work experience. Key factors that shape these processes are given by tragedies, challenges, tensions in their identity and their own judgments about their experience in mining, which leads them to break the female "social identity" and accept the wish of being authors of their own lives, from an ethical project for gender equality.

Keywords: Work experience, gender subjectivity, women, mining

\title{
Processos de subjetividade de gênero nas trabalhadoras da mineração do cobre no Chile. $\mathrm{O}$ caso da divisão o Tenente
}

\begin{abstract}
Resumo
O mercado de trabalho no Chile tem tido uma crescente participação feminina, o qual borrou as margens tradicionais da divisão sexual do trabalho. Isto é evidenciado pelo fenômeno emergente da incorporação das mulheres nos labores produtivas de mineração de cobre. A empresa Codelco tem justificado esta extensão em sua força de trabalho a partir dos benefícios que reporta na produtividade e o ambiente de trabalho. No entanto, pouco tem sido dito desde o ponto de vista dos atores envolvidos. Assim, o presente artigo é ancorado desde a sociologia na experiência de François Dubet, a fim de analisar, através dos relatos das trabalhadoras da divisão do Tenente, os processos de subjetividade de gênero que se estruturam a partir de sua experiência de trabalho. As chaves que dão forma a estes processos são dadas pelos dramas, desafios, tensões em sua identidade e seus próprios prejuízos sobre a sua experiência em mineração, que as leva a definir uma emergente ruptura com seu "Eu social" feminino, e assumir o desejo de ser autoras de suas vidas, a partir de um projeto ético pela igualdade de género.
\end{abstract}

Palavras-chave: Experiência de trabalho, subjetividade de gênero, mulheres, mineração.

\section{Introducción}

Tanto jóvenes como mujeres, sobre todo en los grupos socioeconómicos bajos, tienen mayores dificultades para insertarse de manera estable en un puesto de trabajo en Chile (Sepúlveda, 2009). Sin embargo, la proliferación creciente del acceso de mujeres al mercado del trabajo es indesmentible, e incluso va desdibujando los márgenes tradicionales de la división sexual del trabajo. 
Prueba de ello es la entrada de mujeres a tareas antes realizadas -incluso por ley- solo por hombres, como lo es el trabajo productivo en la minería.

Debemos destacar que este fenómeno ha dado pie a dos lecturas opuestas. Por un lado, se asocia este rostro femenino en el mercado laboral a una consecuencia de la búsqueda por otorgarle rentabilidad a la economía, dadas las recurrentes crisis del sistema capitalista (Girón, 2012). Se evidencia aquí a la mujer como fuerza de trabajo secundaria (Aguiar, 2007), dado que accede principalmente a empleos precarios (Cerda y Cuevas, sin año; Aguiar, 2007; Espinoza y Morris, 2001). Desde este punto de vista, la incorporación de la mujer al trabajo es, por lo tanto, un fundamento del fortalecimiento tanto de la opresión de género como de la explotación del trabajo. Por otro lado, se concibe este fenómeno como fundamento de emancipación de la mujer, dado que representaría un avance en términos de equidad de género (Carosio, 2012), que en el trabajo toma la forma de igualdad de oportunidades. En efecto, desde las corrientes del feminismo liberal, influenciado por Simone de Beauvoir y Élisabeth Badinter, es posible advertir que "una gran parte de lo que se llama las conquistas de las mujeres es sólo la consecuencia de su entrada masiva en el mercado del trabajo" (Touraine, 2000, p. 221). A partir de esta lectura, no solo se busca la igualdad con el hombre en cuanto a tener "las verdaderas recompensas de la vida social -el dinero, el poder, el estatus, la libertad, las oportunidades de realización y autoestima-" (Madoo y Niebrugge-Brantley, 1993, p. 373), sino que también a "revalorizar las actividades de la mujer" (Fridan, 1981), lo cual solo se encontraría con la inclusión de la mujer en la vida pública, como la propia actividad laboral.

Ahora bien, hace falta incorporar una tercera lectura de la inserción femenina al mercado laboral, que considere aquellas relaciones sociales que permitirían hablar del trabajo como espacio de subjetivación, con tal de identificar no solo la reproducción de estructuras sociales y orientaciones culturales dominantes en términos de género, sino, por sobre todo, el modo como estas son 
elaboradas y experimentadas por las propias trabajadoras. En ese sentido, tratándose de mujeres que ingresan a un trabajo mayoritaria e históricamente masculino, resultará pertinente incorporar un enfoque que tome en cuenta la visión de quienes vivencian tal experiencia, pues como dice Touraine:

... el sujeto nace y se desarrolla sobre las ruinas de un ego objetivado por los poseedores del poder y transformado así en sí mismo, sujeto que como individuo aspira a ser productor (y no sólo consumidor) de su experiencia individual y su ambiente social. (Touraine, 2000, p. 230).

Por lo tanto, el propósito de la presente investigación es reflexionar en torno a los procesos de subjetivación de género de las trabajadoras de la minería a partir de su experiencia laboral. Para ello, tomaremos el caso de las operarias de la división El Teniente de Codelco ${ }^{2}$. Se trata de un primer acercamiento a este fenómeno emergente, pues cabe destacar que, en septiembre del 2011, Codelco firmó un convenio de colaboración con el Servicio Nacional de la Mujer (Sernam) que buscaba:

Coordinar acciones conjuntas en ámbitos de difusión y promoción en materias relativas a la inserción laboral femenina en el sector minero; igualdad de oportunidades y de trato para mujeres y hombres dentro de la Corporación; promoción de buenas prácticas laborales con equidad de género dentro de Codelco y el diseño y apoyo de convocatoria para programas pilotos de incorporación de mujeres a las dotaciones de la empresa. (Codelco, 2011).

Por parte de Codelco, esta inserción laboral se justifica a partir de que las mujeres reportan grandes beneficios para la empresa, vinculados a la obtención de mayores grados de productividad y

2 La Corporación Nacional del Cobre de Chile (Codelco) es una empresa estatal chilena dedicada a la explotación minera cuprífera, rubro en el que es la mayor compañía del planeta. 
un mejor clima laboral (Codelco, 2013). Por otro lado, la política gubernamental, que promueve la inserción de la mujer al mundo de la minería, incita a las empresas a la búsqueda de condiciones mínimas de equidad de género, en pos de superar las brechas existentes (Sernam, 2011). Lo anterior se ha traducido en que en Chile la participación femenina en la minería ha aumentado en un 58\% entre 2007 y 2012, y aún sigue siendo baja, con un 7,1\% de la fuerza laboral de la minería (Consejo Minero, 2012). En tanto, en Codelco, la participación femenina se eleva al 8,5\% de la dotación propia (con 1.653 mujeres) (Codelco, 2013). La empresa minera habla de ciertas cualidades particularmente femeninas, que justifican de manera más específica aún la necesidad de incluir en su fuerza de trabajo al sexo femenino. Entre estas, que las mujeres se adaptan más a las capacidades motrices que requiere el manejo de maquinaria, su puntualidad, el que sean responsables, cuidadosas y generen buen ambiente laboral por su capacidad de diálogo y respeto (Codelco, 2011).

Esta serie de características perfila una suerte de "rol" de la mujer en la minería, en la medida en que, a partir de este conjunto de dichos, se dejan en evidencia las exigencias y expectativas que tienen importantes sectores del mundo público y privado hacia la "mujer minera". Desde una mirada crítica, dicho rol puede asociarse a la lectura de la incorporación de la mujer al trabajo como requerimiento del orden económico actual. Según este tipo de interpretación, las transformaciones del neoliberalismo exigirían a los trabajadores el despliegue de estrategias de adaptación, dado que "el nuevo capitalismo tiene y sin duda tendrá cada vez más necesidad de operadores responsables, móviles, polivalentes, capaces de adaptarse a los cambios incesantes, de tomar iniciativas, de reciclarse" (Castel, 2010, p. 27).

Hoy por hoy, estando frente a lo que Touraine llama "modernidad fragmentada", se ha virado a un proceso de individualización en el mundo del trabajo, en el cual es el propio individuo el responsable de su destino. En ese sentido, nuestro interés no estará puesto en la capacidad que tengan las operarias de El Tenien- 
te de adaptarse a las transformaciones del trabajo y la economía -junto a las exigencias con las que cargan en cuanto mujeres-, plasmadas en la precarización, flexibilidad, descolectivización, desprotección social y desarticulación sindical, sino más bien en el modo como se apropian e incorporan de manera crítica y/o reflexiva el rol con el cual se espera que -en tanto mujeres que cargan con facultades distintivas- se desempeñen en la minería del cobre.

Bajo ese contexto, es importante atender procesos de subjetivación que pongan de manifiesto "la penetración del sujeto en el individuo y por consiguiente la transformación -parcial- del individuo en sujeto. Lo que era orden del mundo se convierte en principio de orientación de la conducta" (Touraine, 2000, p. 209). Será fundamental entonces remitirnos al ámbito de la experiencia de estas mujeres e indagar de manera detenida en los procesos de integración a sus nuevos puestos de trabajo, a su nuevo ambiente y condiciones laborales, por medio de la internalización de roles, adoptando estrategias para posicionarse o alcanzar algún fin, junto con el distanciamiento o compromiso que resulta desde el momento en que las trabajadoras adoptan reflexiones y críticas propias respecto a su condición, en tanto actores y dueñas de sí mismas (Dubet, 2010). Por lo tanto, este estudio no es más que el intento por comprender: ¿cómo la experiencia laboral de las trabajadoras de Codelco configura sus procesos de subjetivación de género?

\section{La experiencia laboral de las trabajadoras}

El hecho de que la inserción laboral femenina en Codelco esté motivada por políticas de discriminación positiva que el propio discurso corporativo respalda, que asocian a la mujer con cualidades (que, entre otras cosas, pueden aportar a la prevención de conflictos mineros) tales como el compromiso con el logro de objetivos, la capacidad de manejo de múltiples variables en forma simultánea, la flexibilidad para adecuarse a los 
cambios, la disciplina para actuar de manera ordenada y la capacidad para generar ambientes de trabajo más gratos (Tapia, 2011), no viene sino a plasmar una expectativa social hacia las mujeres, que adquiere una connotación particular en un ámbito productivo de la economía, como lo es la minería. Esto invita a interrogarnos por cómo se expresan dichas expectativas en la experiencia de las involucradas. A su vez, aquello se asocia a una primera distinción conceptual que nos permite asimilar un marco de análisis coherente con nuestro objeto de estudio: la subjetividad de las trabajadoras. Al respecto, Dubet (2010) planteará que esta puede ser concebida desde un proceso mecánico, por el cual los actores se adecuan a su rol, o -al contrario- por un distanciamiento respecto de este.

La primera posibilidad se vincula con una noción de "rol", en la que este da lugar a un personaje que expresa la fusión de los códigos culturales y la personalidad. Esto lleva a que la subjetividad esté formada por las expectativas sociales y por las representaciones del rol al que se adecuarían. En cambio, hablar de "experiencia" implica reconocer un proceso más dinámico en la subjetividad, puesto que lleva a que los individuos se hagan dueños de sí mismos, es decir, que de ser actores pasen a ser sujetos. Por tanto, la subjetivación (sea de clase, de género, política, religiosa, etc.) se identifica con un proceso de distanciamiento frente a los esquemas que vienen dados desde la sociedad, lo que genera, al mismo tiempo, una distancia en relación a sí mismos, que permite apropiarnos de nuestras vidas y convertirnos en sujetos. Acá el énfasis viene marcado en que la subjetividad y los procesos de subjetivación afloran justamente por lo contrario a una adecuación o fusión mecánica de los códigos culturales y la personalidad.

Por lo tanto, situarse desde esta perspectiva implica asumir la propuesta de Dubet (2010) y Dubet y Martuccelli (2000), sobre reemplazar la noción de "rol" por la de "experiencia social", de modo que entendamos tanto la acción social como los procesos de subjetivación que allí se imbrican, procesos que se explican como 
la "autodefinición cultural del sujeto, como el reverso de la imposición de roles por parte del sistema" (Angelcos, 2008, p. 19).

\section{Experiencia social}

Según el propio Dubet, la experiencia debe ser definida:

Como una combinación de lógicas de la acción, lógicas que vinculan al actor a cada una de las lógicas del sistema. El actor es llevado a articular lógicas de la acción diferentes, y es la dinámica producida por esta actividad la que constituye la subjetividad del actor y su reflexividad. (Dubet, 2010, p. 96).

En otras palabras, la experiencia social se forma allí donde los actores están obligados a administrar simultáneamente varias lógicas de acción del sistema social, generando necesariamente una actividad en los individuos, una capacidad crítica y una distancia en relación a sí mismos. Ahora bien, cabe recalcar que dicha distancia, que hace del actor un sujeto, es profundamente social, pues está construida en la propia heterogeneidad de lógicas y de racionalidades de la acción, que Dubet divide en tres: a) lógica de integración; b) lógica estratégica; y c) lógica de subjetivación.

La lógica de integración define la identidad de los individuos de manera clásica, es decir, como una interiorización cultural (o de valores institucionalizados por medio de los roles), que "se vive como una adscripción, una atribución social gracias a la que el actor está constituido como ser social" (Dubet, 2010, p. 103). En ese sentido, la identidad toma la forma de la representación de un papel y posición incorporada y encarnada en los propios cuerpos. Pues está compuesta de una "identidad integradora" que se refuerza a partir del reconocimiento de una diferencia $u$ oposición entre un "nosotros" y un "ellos". Y en aquel conjunto de valores (desde los cuales el actor interpreta la cultura) se logra sostener y asegurar el orden y la identidad, de un modo tal que 
esta se defiende y se mantiene aún en el contexto de un entorno cambiante. Por consiguiente, diremos que, en esta lógica, los "motivos" de la acción apuntan a reforzar, confirmar y reconocer la pertenencia.

En la lógica estratégica, en cambio, los individuos se definen por sus recursos y su racionalidad, en la medida en que las relaciones sociales también se ven afectadas por la puesta en práctica de la identidad integradora en una relación de competencia (o rivalidad) entre intereses individuales o colectivos. Dubet nos dirá también que, en esta perspectiva, el "Yo social" funciona como medio (en cuanto a la posibilidad de influencia, por ejemplo) para la consecución de determinados fines (que en el marco de estas relaciones de competencia dan lugar a varias estrategias). De ahí que "la estrategia implica una racionalidad instrumental, un utilitarismo de la propia acción que pretende consagrar los medios a las finalidades buscadas dentro de las oportunidades abiertas por la situación" (Dubet, 2010, p. 109).Esta lógica, por tanto, implica necesariamente el apoyo de una mínima integración que evite que la competencia se convierta en guerra. Pues la lógica de integración necesariamente está contenida, al menos en este sentido, en la estratégica. Ahora bien, en términos específicos, Dubet nos plantea que la lógica estratégica se revela principalmente en la tensión que le opone a la de integración. Por la misma razón, los valores serán considerados acá como medios o como recursos antes que como fines.

Por otro lado, la lógica de subjetivación define a los individuos como sujetos capaces de reflexión y crítica. Viene a expresarse aquí la distancia de sí que define al sujeto y que le permite, en definitiva, determinar su vida y percibirse como su propio autor. Ello explica que esta lógica aparezca de forma indirecta en la actividad crítica, por lo que a la hora en que el actor pasa a tener un punto de vista diferente al de la integración o de la estrategia, no se puede reducir ni a su rol ni a sus intereses. $\mathrm{O}$, dicho en otras palabras, "...el sujeto está siempre parcialmente 'fuera del mundo'; más concretamente, su identidad está formada por su 
tensión con el mundo, es decir, con la acción integradora y con la estrategia" (Dubet, 2010, p. 116), por lo que, en esta lógica, el actor se distingue de las otras. Es claro entonces que, para Dubet, sean las propias relaciones sociales percibidas como obstáculos para el reconocimiento y la expresión de esta subjetivación, o que adhiera al planteamiento de Touraine acerca de que el conflicto social tenga el reto de controlar la historicidad, puesto que "la parte subjetiva de la identidad es percibida tanto en la desafección como en el compromiso, pues la identificación con la definición cultural de un sujeto prohíbe la adhesión total al Yo, al Nosotros y a los intereses" (Dubet, 2010, p. 116).

\section{Empleo femenino}

Como veíamos, la inserción laboral femenina en la minería es un fenómeno ciertamente emergente. Lo anterior se expresa en que, por medio de la llamada división sexual del trabajo, identificamos la predominancia de una segregación tanto horizontal (mujeres se insertan solo en determinadas áreas de la economía) como vertical (mujeres solo se insertan en determinados puestos de trabajo) (Cerda y Cuevas, sin año). Esto se traduce, por ejemplo, en que la mayor parte de los empleos femeninos se concentran en ocupaciones tales como secretarias, cajeras, telefonistas, entre otros "empleos de oficina", o "trabajadores de servicios y vendedores del comercio y mercados", como vendedoras, camareras, niñeras, ayudantes de enfermería, etc. (Pérez, 2009).

En cambio, una de las ocupaciones masculinas características es el trabajo de los operarios, misma labor que hoy comienzan a desempeñar mujeres en la minería. Ahora bien, si nos remitimos al caso histórico específico de la mina El Teniente de Codelco -el mismo que utilizamos en la presente investigación-, durante el siglo XX (y sobre todo en la primera mitad), nos encontramos con la conformación de una cultura machista que se instala como un antecedente del ambiente laboral minero. Esta cultura machista 
se veía arraigada en la fortaleza física y la capacidad de trabajo duro, en los mitos, ritos y lenguaje (Klubock, 1992), pues se trataba de un mundo de hombres que marcaba -desde una visión androcéntrica- la "identidad minera". Se trata de una cultura laboral marcada hasta nuestros días por la homosociabilidad (Pavez y Hernández, 2014) y la discriminación de género (Salinas, 2012). De ahí, entonces, que hablaremos de "experiencia laboral" para referirnos al modo en que se manifiestan las distintas lógicas de la acción propuestas por Dubet en el ámbito del trabajo, pues entendemos que este ocupa un lugar altamente significativo en la experiencia social de los sujetos. Lo anterior, por tanto, nos permitirá identificar aquellos aspectos significativos (como el género) que van constituyendo los procesos de subjetivación en estas trabajadoras.

\section{Subjetivación de género}

A raíz de la lógica de subjetivación propuesta por Dubet, y dadas las características propias del medio laboral en el que se enmarca la experiencia de las trabajadoras de Codelco, nos parece relevante utilizar una óptica particular en los procesos de subjetivación en dichas mujeres. Nos referimos a lo que llamaremos "subjetivación de género", es decir, un proceso de apropiación del sí mismo desde la experiencia laboral en términos de los significados socialmente significativos en su dimensión de género. Tiene relación con la desafección o el compromiso derivado de la distancia de sí que define al sujeto de género sobre la base del rol que los códigos culturales y los discursos oficiales le exigen a la "personalidad" femenina -en este caso, en tanto trabajadoras de la minería.

Por consiguiente, los aportes de Dubet se entrecruzan con un enfoque de género, en el que nos parece relevante reconocer la existencia de una especie de habitus masculino y femenino, que busca naturalizar los roles de género (y que Bourdieu también denomina "subjetividad socializada") arraigados en esquemas 
de visión y división entre los sexos. Estos funcionan como esquemas de percepción del pensamiento y de la acción, que los sujetos incorporan en el marco de las relaciones de dominación de género o, en términos del propio autor, la existencia de:

Una construcción social arbitraria de lo biológico, y en especial del cuerpo, masculino y femenino, de sus costumbres y de sus funciones, en particular de la reproducción biológica, [lo] que proporciona un fundamento aparentemente natural a la visión androcéntrica de la división de la actividad sexual y de la división sexual del trabajo y, a partir de ahí, de todo el cosmos". (Bourdieu, 2007, p. 37)3.

En ese marco, no podemos tampoco dejar de considerar que dichos esquemas de género a la vez se arraigan en medio de relaciones de producción capitalista que, históricamente, han construido la imagen femenina bajo el binario producción/reproducción, asociando ideológicamente a la imagen femenina con la fertilidad, fragilidad y un sinfín de características que han sido los pilares de la división sexual del trabajo en la sociedad moderna. Frente a ello, y dada la problemática que atraviesa esta investigación, Judith Astelarra dirá que "la entrada de la mujer al trabajo asalariado ni es el fundamento de su liberación, ni la equipara con el sector asalariado masculino" (Astelarra, 2003, p. 82).

\footnotetext{
3 Aclararemos que, antes de adherir a la sociología de la reproducción que plantea Bourdieu, utilizamos algunos de sus aportes conceptuales por su rendimiento analítico, que nos permite dejar a la vista de manera patente el orden de género que prevalece en la sociedad. Igualmente, por motivos de espacio nos marginaremos de la interesante discusión que ha surgido desde lecturas críticas y desde una sociología del individuo sobre la obra de Bourdieu. En particular, haremos la única salvedad de que los aportes de Bourdieu en esta investigación nos permitirán reflexionar acerca de la tensión entre las disposiciones y la conciencia (la reflexividad) que, contrariamente a Bourdieu, no miraremos desde una concepción del sujeto remitida a parámetros homogéneos que lo opacan por la estructura social y que reducen su socialización a un proceso meramente reproductivo, en el que el sujeto está definido antes por un rol o disposición social (vinculado al modelo del personaje social) adquirido. Antes bien, pondremos atención a dicha tensión desde la experiencia de los sujetos y su capacidad productiva de lo social. Para profundizar en este debate, revisar Martuccelliy Singly (2012); Dubet y Martuccelli (1999); Dubet (2010); Touraine (1969).
} 
Esto, entonces, nos invita a pensar justamente en los procesos que atraviesan las mujeres en relación a su género, dada su incorporación a una labor históricamente masculina, como es el trabajo directo en las faenas productivas de Codelco. Incluso, en un medio laboral con estas características, podríamos adherir en buena parte a las consideraciones de Izquierdo (2004), cuando plantea que:

La división sexual del trabajo coloca a las mujeres en el terreno de lo particular. Y esto ocurre tanto desde el punto de vista de sus actividades económicas inmediatas, como en sus disposiciones psíquicas, los principios éticos que informan su conducta y sus habilidades y capacidades cognitivas. (Izquierdo, 2004, p. 8).

Pues si bien en este ámbito la actividad económica inmediata no la hace particular, como en el trabajo doméstico, es posible identificar características asociadas al trabajo femenino en labores históricamente masculinas que sí le confieren cualidades y facultades específicamente referidas por su condición de género. A la vez, si bien no nos inmiscuiremos en el debate acerca de la existencia de una ética propiamente femenina, sí consideramos que existen expresiones propias de la subjetividad en el caso de estas mujeres trabajadoras, dentro de la cual se abren posibilidades para pensar en los procesos de subjetivación en términos de género.

\section{Cuadro $\mathrm{N}^{\circ} 1$. Síntesis del marco teórico}

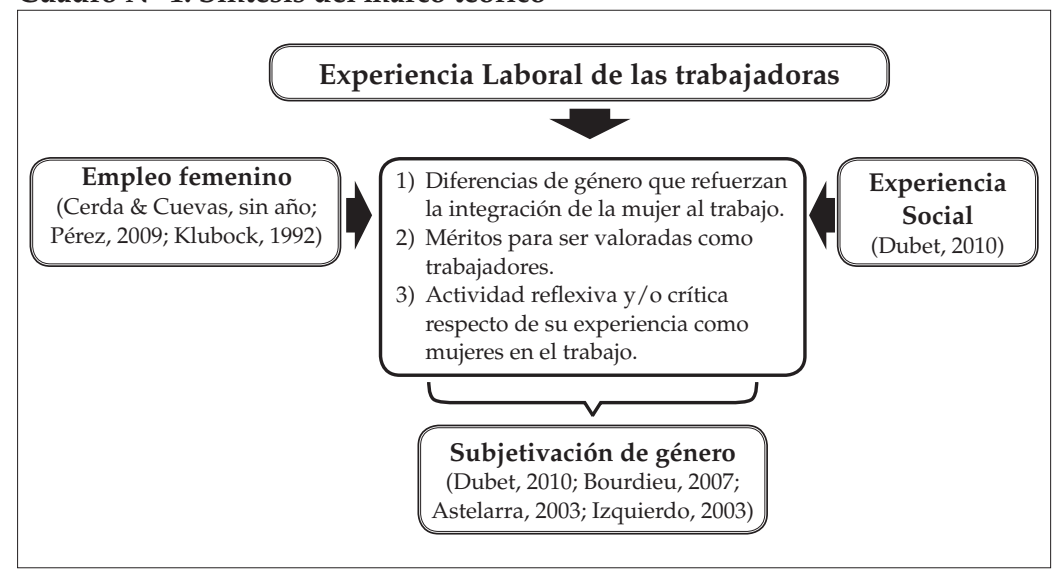

Fuente: Elaboración propia 


\section{Metodología}

Para efectos de esta investigación, se desarrollaron seis entrevistas semiestructuradas a trabajadoras de la división El Teniente, con el fin de recabar y producir información valiosa sobre los procesos de subjetivación de género que van estructurándose a partir de su experiencia laboral. Para ello se ha utilizado la técnica del análisis de contenido, con el fin de plasmar los horizontes de sentido que se dejan de manifiesto en los discursos de las entrevistadas. Asimismo, los casos examinados corresponden a trabajadoras que llevan entre seis meses y dos años trabajando en El Teniente. Son mujeres que han ingresado a condiciones laborales estables y formales, en su mayoría, luego de un proceso riguroso de selección que, a su vez, se condice con que estas son pioneras en cuanto a inserción laboral femenina a la minería. Lo anterior impacta en la actitud hacia el trabajo y al discurso de la empresa.

El caso estudiado se debe a un criterio de viabilidad, en el marco del tiempo acotado y los pocos recursos para asumir más casos, o uno más representativo respecto de la dotación total de mujeres en Codelco. La división El Teniente cuenta con solo un $4,8 \%$ de mujeres, en relación a la dotación propia, a diferencia de la división Gabriela Mistral, en la que se concentra un 18,2\% (Codelco, 2013), es decir, la que cuenta con mayor dotación femenina de Codelco en Chile. Debido a esto, nos vimos obligados a seleccionar los casos de manera aleatoria.

\section{Casos Seleccionados}

\begin{tabular}{|c|c|c|c|c|c|c|}
\hline Trabajadora & Edad & Estado Civil & $\begin{array}{c}\text { Situación } \\
\text { Familiar }\end{array}$ & Empresa & $\begin{array}{c}\text { Tiempo en } \\
\text { El Teniente }\end{array}$ & Cargo \\
\hline A & 35 & Divorciada & 3 hijos & Codelco & 3 años & $\begin{array}{c}\text { Operaria } \\
\text { (máquina } \\
\text { diversa) }\end{array}$ \\
\hline B & 34 & Soltera & 1 hijo & Codelco & 2 años & $\begin{array}{c}\text { Operaria } \\
\text { (palanquera) }\end{array}$ \\
\hline C & 33 & Divorciada & 2 hijos & Contratista & 6 meses & $\begin{array}{c}\text { Operaria } \\
\text { (jumbera) }\end{array}$ \\
\hline D & 25 & Soltera & Sin hijos & Codelco & 1 año & Operaria \\
\hline E & 49 & Divorciada & 3 hijos & Contratista & 1 año & $\begin{array}{c}\text { Operaria } \\
\text { (jumbera) }\end{array}$ \\
\hline F & 45 & Divorciada & 2 hijos & Contratista & 1 año & $\begin{array}{c}\text { Operaria } \\
\text { (jumbera) }\end{array}$ \\
\hline
\end{tabular}

Fuente: Elaboración propia 


\section{Resultados}

\section{Diferencias de género como reforzamiento de la integración de las mujeres en la minería}

En esta primera sección, nos encontramos con que las trabajadoras de El Teniente se hacen parte de sus labores a partir del reconocimiento de ciertas cualidades femeninas. Pues si bien asumen como naturales las diferencias en cuanto a fuerza física con sus compañeros de trabajo, no así respecto de las capacidades humanas para la realización de sus labores como operarias, las que asignan en términos de igualdad. Sin embargo, al momento en que afirman tener cualidades, estas las interpretan en tanto atributos de género que delimitan su identidad y que asocian con ciertos aportes distintivos al interior de la minería. "Las mujeres somos más responsables, en ese sentido como que nosotras no fallamos, no somos buenas pa' la farra, por ejemplo, somos más responsables, más puntuales. Somos más eh, (...) multifuncionales." (Trabajadora B). Vemos de qué modo esta diferenciación frente al desempeño laboral de sus compañeros se ve acompañada de una evaluación crítica hacia estos, quienes serían, entre otras cosas, menos comprometidos con el trabajo. A la vez que una identificación, desde su experiencia, con aquellas habilidades por las cuales las empresas mineras -y en particular Codelco, a raíz del acuerdo que establece con Sernam- se interesaron en la incorporación femenina a su fuerza de trabajo (motricidad fina, amabilidad, cuidado, puntualidad y responsabilidad).

Resulta interesante destacar que, a este respecto, varias de las entrevistadas hacen ver que dichas cualidades no responden a una suerte de naturaleza femenina, sino más bien a razones culturales o de crianza, dando cuenta de una noción amplia del género. Sin embargo, a pesar de reconocer compañeros igual de responsables que ellas, por ejemplo, estos permanecen como casos excepcionales, pues se corresponden antes con un traslado de cualidades femeninas desde el ámbito reproductivo hacia el ámbito productivo. Así, estos atributos los interpretan desde 
su condición de género, para explicarse la oportunidad laboral de la que se sienten -y son- pioneras en la minería y, a su vez, desde los cuales se reconocen como un aporte a la misma. Pues bien, será aquel lugar distintivo, por las cualidades de las trabajadoras, lo que las llevará a diagnosticar ciertos efectos positivos de su ingreso a la minería en el ambiente laboral. Destacan cambios en hábitos de higiene personal, cuidado de las máquinas, uso del lenguaje, medidas de seguridad y prácticas de solidaridad. Como señala una de las trabajadoras (refiriéndose a la maquinaria), "los compadres empiezan a cachar que es muy bien valorado que tú tengái el equipo limpio, que tengái todos los focos" (Trabajadora C), o, inclusive, que "entre ellos ha mejorado también la convivencia po, y el diálogo po, si antes se trataban a puro garabato, ahora hay más diálogo y armonía en el trabajo" (Trabajadora D). Otras señalan que los hombres comienzan a ir más limpios o adoptan prácticas de solidaridad con sus compañeros (como ayudar al otro en tareas complejas, por ejemplo). Estos aportes al ambiente laboral ciertamente actúan como elemento cohesionador con sus pares, a la vez que las hacen sentirse como parte integrante de la minería.

Ahora bien, en esa integración se destacan también dos tipos de lazos o relaciones de género que establecen las y los operarios, en tanto compañeros de trabajo y pares. Por un lado, desde los hombres se establecen relaciones de protección, en las que estos ven a sus compañeras como si fueran sus esposas o hijas: "El hecho de cuidarnos, o sea, yo creo de que el hecho que el hombre tenga su familia lo hace ser más comprensivo en este ámbito laboral, al compartir con mujeres. Y eso, yo creo que eso, el hecho de tener hijos, de tener esposa, yo creo de que ellos en el fondo, no sé po, un poco se imaginan el hecho de que sea tu esposa o tu marido el que está trabajando en minería" (Trabajadora F). Llama la atención la analogía con el lazo familiar en el marco de las relaciones de género que se van configurando con la entrada de la mujer a la minería, pues, al ser un trabajo riesgoso, pareciera que los hombres tienden -al igual como las mujeres respecto de sus cualidades- a traspasar su rol protector 
en el hogar hacia el ámbito productivo, al menos cuando ponen en práctica esta lógica de protección hacia sus compañeras.

Por otro lado, existe un tipo de lazo en el cual las trabajadoras pasan a ser, para los hombres, aquel apoyo afectivo y de confianza que no satisfacen con los pares de su mismo sexo, y podríamos agregar, desde Connel (1995), que ello se debe a la prohibición del sistema patriarcal a ciertas formas de emoción o afecto), lo que los lleva a acudir a ellas para compartir problemas y situaciones personales: "me cuentan cosas que yo creo que ni a su ganchito le contarían, pero me cuenta a mí, ni a su junta se lo contarían, me lo cuentan a mí po, y yo qué onda, pero si me quiere contar, problema de él po. Eso me ha pasado con los viejos arriba, es como mucha confianza (...) porque me cuentan toda su historia (...) entonces pa ellos también ha sido como terapia" (Trabajadora C). Estos tipos de lazos, por lo tanto, parecieran ampliar las dinámicas relacionales en el trabajo, en tanto que para los hombres la mujer pasa a ocupar un lugar, por decirlo así, de hermandad, como también aquella con la cual puede mostrar su mundo afectivo.

Tenemos entonces que las diferencias de género en el ámbito laboral actúan como fundamento cohesionador para estas mujeres, en la medida en que les asigna un lugar de pertenencia desde el cual se reconocen y distinguen de sus compañeros hombres. En ese sentido, sienten ser un aporte tanto a sus pares como a la empresa. Como bien nos dice Dubet, ocurre que:

La forma elemental de esta relación opone el intragrupo (in group), que no existe más que en la afirmación constante de su diferencia y de su distancia, al extragrupo (outgroup). La identidad integradora no se mantiene sino es en esta relación; la "necesita" al mismo tiempo que esta relación la engendra. (Dubet, 2010, p. 106).

En suma, estas diferencias de género no solo refuerzan la integración de las trabajadoras, sino que también las requieren, pues, como bien han dicho algunos estudios contemporáneos sobre desigualdad de género, "la relevancia de la distinción de 
grupo como el sexo o la raza es especialmente alta en el lugar de trabajo cuando un grupo es sólo una pequeña minoría de los trabajadores actuales" (Ridgeway, 2011, p. 111). Sin embargo, cabe precisar que el valor de la igualdad que las trabajadoras manifiestan (en términos de las capacidades para desempeñarse en las faenas productivas), adquiere aquí una connotación propiamente integradora, dado que se plantea como un fundamento de su identidad, por el cual son aceptadas en la minería. Ahora bien, si este mismo valor puede pasar a constituirse en el punto nodal de una crítica -como diría Dubet-, entonces estaría inscrito en la lógica de subjetivación, como abordaremos en la tercera sección.

\section{Méritos para ser valoradas como trabajadoras}

Al hablar de los méritos que deben cumplir las trabajadoras de El Teniente, nos referimos a ciertos elementos indispensables de los que se deben hacer cargo para lograr su valoración como tales, pues al ser un medio históricamente masculino, deben lidiar con una serie de actitudes y prácticas mermadas por una cultura de trabajo que funciona con base en lógicas de género que, si no saben enfrentar, pueden, entre otras cosas, amenazar su integración a la minería. Pues las mujeres se conforman en el punto de mira, al ser minoría frente a un grupo con mayor estatus en el orden de género y, por tanto, la visibilidad que tienen frente a la empresa y sus compañeros implica la presión del desempeño en el trabajo (Ridgeway, 2011).

Sin embargo, debemos considerar que la mayoría de estas mujeres mineras, si no ha tenido experiencia previa en la minería, sí la ha tenido en "trabajos masculinos". Esto es determinante para entender que su inserción al ambiente laboral no les aqueja mayormente por enfrentarse a un "mundo de hombres", lo que no las exime de la necesidad de utilizar estrategias, pues estas responden, en gran medida, al ámbito específico de su nueva experiencia laboral, a lo duro del trabajo y las nociones de género asociadas al mismo en el marco de la división sexual tradicional 
del trabajo que, en el caso de la minería y en particular de la división El Teniente, se registra con alta carga del pasado ${ }^{4}$. En ese sentido, comprendemos que los hombres no ven siempre a las mujeres como un compañero de trabajo más, y tengan actitudes y prácticas que, antes que nada, reflejan las jerarquías del sistema sexo-género, por las cuales las mujeres representan al sexo débil. De ahí que las mujeres mineras intenten demostrar lo contrario y estén, por tanto, obligadas a inscribirse en la lógica estratégica de la que nos hablaba Dubet.

En primer lugar, las entrevistadas ponen en evidencia que, frente a ciertas dificultades -en el marco de las relaciones laborales-, tendrán como imperativo común ser fuertes en términos de carácter y, de tal modo, ser capaces de superponerse a determinados escenarios: "uno tiene que tener un carácter súper fuerte también ahí, ser bastante directa con las cosas que decí. No ser tímida, porque si uno es muy tímida se te suben por el chorro, se las dan de galanes algunos. Hay de todo. (...) carácter fuerte nomás, y si no lo tení tienes que forjarlo porque si eres muy tímido, no" (Trabajadora B). Inclusive habrán casos en los cuales se interpretará que hay un "tipo de mujer" (asociado a esta fortaleza) que el minero "aprueba" para considerarla como compañera de trabajo: "ellos quieren mujeres pero quieren mujeres fuertes también, ellos no quieren una mujer que pucha seái una carga, de andar cuidándola, no quieren sentirse culpables porque una mina quedó atrás, cachái. Pa ellos también es un cargo, porque tú también les dai un peso estando ahí" (Trabajadora C). En ese sentido, las trabajadoras deben adecuarse a este "mundo de hombres", en el que priman -podríamos decir- ciertas leyes

\footnotetext{
4 Esto se refleja en la cultura machista de los trabajadores de la minería, desde la cual emergió, por ejemplo, el mito de que el ingreso de mujeres a las faenas productivas era signo de mala suerte. Para estos efectos revisar: Klubock, T. 1992. Sexualidad y proletarización en la mina El Teniente. Proposiciones Vol.21. Santiago de Chile: Ediciones Sur; Klubock, T. (1995). Hombres y mujeres en El Teniente, la construcción de género y clase en la minería chilena del cobre 1904-1951. En L. Godoy et al. Disciplina y desacato. Construcción de identidad en Chile, siglos XIX y XX. Santiago de Chile: Coedición SUR/CEDEM, 110-123.
} 
"consuetudinarias" en la relación de trabajo, otorgadas, al parecer, por el patrón social de la masculinidad ${ }^{5}$, entendida desde la fortaleza física y psicológica. Así, estas mujeres vislumbran la necesidad de relacionarse con sus pares desde la utilización de aquellas reglas dadas y, de tal forma, igualarse a la noción de lo que es ser trabajador de la minería para los hombres. De otro modo, la mujer queda relegada a una posición de debilidad y como grupo problemático para el buen desempeño de las labores en la mina.

Por tanto, las trabajadoras deben hacerse de aquel carácter fuerte para su propia protección, la que deben saber administrar para demostrar respeto, pues requieren, en ciertas situaciones, ser capaces de fijarles límites a sus compañeros. Una trabajadora lo plantea del siguiente modo: "Porque no podí ir y echarle garabatos a los viejos porque te tratan así o porque te hacen las cosas difícil, sino que demostrando que podíai hacer más que ellos a lo mejor po, cachái" (Trabajadora A). En ese sentido, será bajo el recurso al diálogo como la mujer intentará exigir respeto y, por sobre todo, aludiendo a destacarse en sus tareas al interior de las faenas productivas. Es decir, demostrando que están ahí para trabajar antes que para otra cosa. Ahora bien, las mujeres mineras intentarán destacar por su buen desempeño laboral, pero no así por su condición de género. Buscarán, antes que todo, pasar desapercibidas, ser valoradas como uno más en las relaciones laborales, y no desde un trato especial, como acá se plantea: "yo no encuentro que tengamos un trato especial, soy uno más no más po. No me aprovecho de mi condición, de que por ser mujer me tienen que dar preferencia por eso, no, no marco esa diferencia yo" (Trabajadora D). Como vemos, la elección tomada de no marcar una diferencia o aprovecharse de ser mujeres, radica en el intento por igualarse en el trabajo, y no sobreponer su condición de género a su condición de trabajadoras, sino más bien al contrario.

Al respecto se recomienda revisar: Connel, R. (1995). The social organization of masculinity. Berkeley: University of California Press. 
De tal modo, las operarias se van enfrentando a un mundo laboral en el que deben saber cómo actuar o cómo mostrarse, pero donde incluso mantener una buena relación con sus pares se vuelve un interés, por ejemplo, para recibir ayuda en situaciones que la requieran. Esta mujer lo relata: "no ser pesá, para que no te tengan mala también, que te creí la muerte, despué cuando tení un problema o que, requerí de ellos, tení problemas con ellos porque no te van a, te van a tener mala. No te van a querer ayudar" (Trabajadora B). Se deja en claro que acá opera una lógica estratégica antes que de integración, pues más que los reportes que sus cualidades distintivas implican en el ambiente laboral y, por tanto, en la identidad integradora de las trabajadoras, estamos ante un razonamiento instrumental y de conveniencia, que simplemente es uno más, y funciona como medio para desempeñar con más garantías y seguridad el trabajo al que se enfrentan.

Dicho esto, en esta sección se registra una noción sobre el "ser trabajador", en la cual las mujeres buscan posicionarse, de modo que no queden fuera de aquella categoría y puedan, por decirlo así, competir en las mismas condiciones. El hecho de que algunos trabajadores comienzan a rechazar la incorporación de las mujeres, en la medida en que las ven como una amenaza, da cuenta de una reacción (o en algunos casos temor) por notar un nuevo actor de competencia en el trabajo. Más aún cuando este llega con una serie de conocimientos técnicos y con la preparación pertinente de manejar la maquinaria más grande y tecnológica que varias de las entrevistadas operan, mientras que a ellos no se les permite. De tal forma, se entremezclan tanto la cultura machista como la autoprotección de un nosotros (hombres) frente a un ellos (mujeres), que aparece en esta suerte de "campo de juego" con nuevos miembros. De ahí que las trabajadoras deban ser hábiles y conocer el modus operandi de sus pares hombres, con el fin de que logren obtener un buen manejo en sus relaciones laborales, se posicionen frente a ellos como un legítimo par y, por lo tanto, no se arriesguen a ser carcomidas por el ambiente masculino y masculinizante de la cultura minera. Más todavía si lo que pretenden 
a través de estas estrategias es ganarse el lugar de una igualdad, es decir, que las valoren en cuanto trabajadoras y no desvaloricen su lugar en el trabajo por su condición de género.

\section{Actividad reflexiva sobre su experiencia laboral}

Según Dubet (2010), los individuos son definidos como sujetos capaces de reflexión y crítica, como representación de la autenticidad y de la creatividad humana. Cabe advertir que "no necesariamente tenemos que pensar en las formas de acción más conflictivas para poner en evidencia una reflexividad que, aunque no sea necesariamente crítica, da sustento a una capacidad crítica permanente" (Dubet, 2010, p. 96). Lo importante, en ese sentido, será atender la lógica de subjetivación de género en la experiencia laboral de las trabajadoras, más allá de la intensidad que adquieran los contenidos normativos en su actividad reflexiva, pues lo crucial es la perspectiva elegida por los propios actores. Así, nos encontramos ante cuatro grandes momentos en la experiencia laboral que darán forma a los procesos de subjetivación de género en las trabajadoras operarias de El Teniente: a) sus dramas; b) las tensiones en su identidad de género; c) los desafíos que asumen, y d) su propia elaboración reflexiva.

\section{Dramas en la experiencia}

En primer lugar, estas mujeres deben ser capaces de superar situaciones que representen lo dramático en su experiencia. Una de ellas, y que se repitió en las entrevistadas, dice relación con la represión que ejercen sobre sí mismas en el trabajo para expresar sus sufrimientos individuales, en razón del estatus distintivo -y marcadamente femenino- en las relaciones de género que provocan esos afectos. De ese modo lo manifiesta una de ellas: "Tení que ignorar muchas cosas a veces, tení que, no sé, de repente no llorar delante que te vean tus compañeros, porque ese ya es como un punto que, de los cuales ellos, no sé po, te van catalogando como, te hacen ver como distinta a ellos, cachái" (Trabajadora A). Observamos que las 
expresiones afectivas ellas las identifican como signos de debilidad que demuestran cómo se imponen las prácticas masculinas y masculinizantes en la minería. Igualmente, los motivos de sus sufrimientos pueden ir desde no soportar la soledad que muchas veces acompaña sus labores, la desconexión radical con el entorno y sus familias (dadas sus jornadas de trabajo al interior de la mina), la intensidad y dificultad de la operación de las máquinas, como también las situaciones de conflicto y tensión en sus relaciones laborales. En ese sentido, algunas de las entrevistadas se enfrentan a dinámicas bastante complejas (y que ciertamente provocan una marca en su experiencia), como son las situaciones de acoso por parte de sus compañeros de trabajo: "Este caballero va y me, yo tenía frío, hacía más frío ese día. Empecé yo como a sobarme las manos y me tocó las manos. Después me empezó a tocar la pierna. Y yo le dije 'no me toque', y ahí se puso como tartamudo. (...) después si yo le dejo que me toque la pierna quizás qué me toca. Entonces ahí tuve que estar alerta, 'no me toque' le dije, 'es que es un cariño no más', 'no, es que yo no necesito cariño, si tú lo vuelves a hacer te acuso'" (Trabajadora B).

Por su parte, estos dramas en la experiencia se hacen evidentes en prácticas indignas que deben realizar, en razón de condiciones laborales que aún no se adecuan a la fuerza de trabajo femenina y que expresan una patente precariedad en el trabajo. Dicha precariedad es vivida -en algunos casos- de manera más intensa por las mujeres que por los hombres, tal y como ocurre con el problema de los pocos o nulos baños con que cuentan en sus jornadas de trabajo. Al respecto, una de las entrevistadas dirá: " $p a^{\prime}$ ellos es fácil orinar po, pero pa' mí, ¿qué hago yo? Me tengo que ir detrás de la máquina nomás, y escondida entre medio de las ruedas por que a cada rato pasan vehículos. Imagínate, imagínate cuando andamos con la regla, ¿cómo?, ¿cómo vamos al baño?" (Trabajadora E). A su vez, otras lo expresan en términos de impotencia y frustración para con la empresa, al no conseguir reparo: "lo primero que dice la carta de valores es 'respeto y dignidad a las personas', pero cuando yo voy al baño y tengo que defecar en cualquier lado yo encuentro que esa primera frase no se cumple, por 
lo menos en mi área yo no tengo donde ir, y no encuentro que sea un respeto para mí, es denigrante. Y esas cosas, bueno, yo llegué a hablar con el gerente en mina y no hay caso" (Trabajadora B). Si bien hay énfasis distintos en el resto de las entrevistadas, las que, o simplemente se adaptan, al punto de regular su cuerpo para ir al baño solo en horarios de almuerzo, o lo ven como un problema momentáneo que no les afecta mayormente.

El caso de la Trabajadora B es el que presenta más claramente un impacto en la subjetividad, tanto de este caso, como el de las prácticas de acoso. Este ejemplo nos muestra que "los actores viven con más facilidad su actividad como sujeto en el sufrimiento que en la dicha" (Dubet, 2010, p. 91). Aquello se condice con la Trabajadora B, pues será el caso paradigmático de subjetivación de género, por donde se inmiscuirá, a su vez, con procesos de subjetivación política, que no vimos con claridad en el resto de las entrevistadas.

\section{Tensiones en su identidad de género: entre la "feminización" y la "masculinización"}

En un segundo momento hallamos ciertas tensiones en las entrevistadas, que les llevan a enfrentarse a su identidad femenina y al impacto que en ella genera el predominio masculino en la minería, pues, como bien nos advierte Connel, "la masculinidad, así como la feminidad, siempre está asociada a contradicciones internas y rupturas históricas" (Connel, 1995, p. 8). Al respecto, vemos que, por un lado, surgen ciertas resistencias en las trabajadoras ante los estereotipos tradicionales de la mujer (principalmente a ser vistas como el sexo débil) y que sienten presentes en su ambiente de trabajo (expresado en cómo las miran sus compañeros). Así lo expresa una operaria: "tampoco te diría yo 'ah voy a renunciar', no, esto es pa mí, y yo me la puedo, y sé que soy mejor que ellos, y lo he comprobao porque yo perforo y yo doy frutos a la empresa" (Trabajadora E). En esta seguridad y convicción de que la mujer puede ser mejor que el hombre se deja entrever una suerte de 
disputa entre los sexos que, en su inscripción dentro de la lógica del sujeto, implicará una aparente apropiación del ser mujer en la minería, a través de la producción de valores de género que le otorgan mayor predominancia al desempeño laboral femenino que al masculino, como signo de resistencia a la hegemonía masculina de la fuerza de trabajo minera.

Por otro lado, se dan casos como el de la siguiente entrevistada: "tú soi un hombre más po, incluso parecí hombre (...) Tú tomái herramientas, andái con grasa, transportái aceites pa' los jumbos, no sé po, sacái horquillas y las reponí; no, si es totalmente distinto, no es lo mismo que una mujer afuera, cachái. (...) descansar no más, querí estar con los tuyos, querí pescar a tus hijos, querí tomarte una cerveza en el sillón y que nadie te diga nada. Te poní como hombre, de verdad, de mirar la tele y moverla" (Trabajadora C). Cabe señalar que el conflicto en la identidad que acá se aprecia no es vivido como conflicto, sino más bien como una realidad asumida, que implica no solo comprender más a los mineros, sino que, a su vez, reconocer niveles de mimetización con los mismos, o la incorporación de orientaciones asociadas tradicionalmente a la mentalidad masculina.

Ambos casos resultan interesantes de poner a la vista, dado que reflejan una tensión constante en las entrevistadas, que consiste en que sus propios modos de administrar las estrategias para ser valoradas y legitimadas ante sus compañeros y la empresa entran en conflicto con su feminidad. Algunas expresan ese conflicto desde la resistencia a la masculinización de sus identidades, o la necesidad de afirmar el hecho de ser mujeres, a partir de su resignificación en el trabajo (como el caso de E). En tanto otras asumen sin resquemores mimetizarse con los hombres en torno a ciertas prácticas y actitudes, no viendo allí una amenaza, a pesar de que implique ciertos niveles de masculinización de sus identidades (como el caso de C). Diremos también que esta tensión y disputa -aún difusas- dela identidad femenina parece ser uno de los significativos impactos que va teniendo la experiencia laboral en los procesos de subjetivación de género y que, por tanto, implican configuraciones identitarias para los trabaja- 
dores (hombres y mujeres). Lo interesante, entonces, es que allí residen las elaboraciones y contenidos que las trabajadoras le van asignando a su experiencia laboral, desde su propia capacidad de crearse a sí mismas y autodefinirse en tanto sujetos de género. Esto se expresa con mayor claridad en aquellas mujeres en las que brotan elementos de resistencia a la definición cultural y tradicional de la mujer, pues en los otros casos resulta más difícil encontrar -al menos a este respecto- la lógica de subjetivación, debido a que carecen de niveles de reflexividad sobre aquellas prácticas y actitudes por las cuales puedan estar masculinizándose.

\section{Asumir desafíos}

Sin tener resuelta dicha tensión, las trabajadoras presentan de manera transversal- ciertos desafíos que plasman un momento importante en el registro del sujeto. Entre ellos, el que aparece de manera más notoria es el de demostrar que la mujer puede hacer las mismas labores que los hombres: "O sea yo creo que la mujer que quiere puede, es una cosa de actitud y de querer. (...) somos capaces, podemos hacer trabajos y lo que no nos imaginamos" (Trabajadora F). Aquí reside una clave importante para comprender de qué manera aparece la lógica de subjetivación en las trabajadoras de El Teniente, pues se reconoce una demanda por igualdad entre los sexos. Así, su desempeño será crucial para demostrar que la mujer puede desarrollar las tareas productivas en la minería tanto como un hombre. Ahora bien, este interés no implica -de por sí- la presencia de subjetivación, pues, como ya veíamos en la primera dimensión del presente análisis, el valor de la igualdad también adquiere sentido desde una lógica de la integración. Empero, en la mayoría de las entrevistadas, este se evidencia como un punto central en el desarrollo de su reflexividad y crítica, ya que a partir del desafío de demostrar la igualdad es como van revistiendo de un contenido propio el lugar de la mujer en la minería y en la sociedad, así como también sus críticas hacia el 
machismo y a las propias empresas mineras, lo que se hará más evidente en el siguiente eje.

Pero existen también otros desafíos que nos permitirán entender mejor cómo va emergiendo la lógica del sujeto en términos de sus contenidos. No deja de ser patente la necesidad por demostrar, por ejemplo, que la mujer que trabaja en minería lo hace a causa de lo mismo que los hombres: por necesidad. Aquello resulta de gran relevancia para las entrevistadas, en la medida en que no son consideradas como iguales por sus compañeros. Las primeras impresiones que van teniendo al llegar a la minería lo hacen patente, pues las trabajadoras recalcan que, hasta que no fijan los límites, son tratadas muchas veces desde el "piropo", la broma o una imagen sexualizada de la mujer. De ahí, en parte, que las estrategias sean una necesidad, pero también el desafío de demostrar la igualdad. Esta trabajadora lo expresa del siguiente modo: "la idea es eso, hacerles entender que no vai a eso, que tú también tení una familia, que tení que mantener, que...de hecho yo, mi lema, es siempre cuando llegaba a un trabajo, yo les decía 'oye, yo no vengo a buscar amigos, yo vengo a trabajar porque tengo cuatro hijos en mi casa, nada más'" (Trabajadora A). Al afirmar su identidad desde una igualdad con sus pares hombres (ser trabajadores), las mujeres van intentando tomar un rol activo frente a las estigmatizaciones de género de las que son víctimas. Se abren paso entonces a un desafío importante en su afirmación como sujetos, pues comienzan a promover y producir nuevas relaciones laborales que toman distancia de los estereotipos de género que les son asignados.

Por su parte, las madres solteras o divorciadas que entrevistamos dejaron en claro el desafío personal de ser capaces de hacer frente a su doble jornada laboral, como dijo una de ellas: " $m i$ trabajo es harto pesado, igual tengo que hacer turnos y todo, pero yo también tengo que llegar a mi casa y tengo que ver a mi hija igual. Entonces igual yo tengo que preocuparme de hacer las tareas con ella, prepararle la leche, vestirla, peinarla, y el hombre no lo hace (...) Entonces claro, nos hemos querido insertar a la sociedad, a la parte laboral igual que el 
hombre, pero al mismo tiempo también tenemos que seguir siendo amas de casa" (Trabajadora C). Las entrevistadas remarcan, en ese sentido, una diferencia con sus compañeros de trabajo, en la medida en que la mayoría de ellos son el único sostén económico de sus familias, mientras que sus mujeres trabajan solo como dueñas de casa. Por tanto, la doble jornada laboral a la que se enfrentan, implica que, por un lado, las trabajadoras de El Teniente logran desplazar las barreras tradicionales de la división sexual del trabajo, obteniendo total independencia económica (pudiendo sostener sus hogares), y, por otro, que deben seguir velando por las tareas domésticas. Esto conlleva a que las mujeres mineras reafirmen el desafío de demostrar que trabajan por necesidad, pero con "costos" mucho más altos en términos de sacrificio y esfuerzo. La doble jornada laboral se convierte entonces en una marca importante en sus trayectorias de vida, para valorizarse y afirmarse desde una identidad luchadora que las distancia de los esquemas de género por los cuales las mujeres se reducen a la fragilidad. Así, llegamos a otros de sus desafíos más sentidos: demostrar no solo que son capaces, sino que, a su vez, representan del mejor modo posible al género femenino: "estamos abriendo el camino a muchas mujeres más, que se atrevan como nosotras, porque no es fácil, $p a^{\prime}$ mí no ha sido fácil" (Trabajadora E). Se adquiere entonces, una responsabilidad de género que actúa como imperativo moral a la hora de enfrentarse a sus labores en la minería. Las trabajadoras recalcan sentirse pioneras y, por ende, que lo deben hacer bien, pues dependerá de su desempeño laboral el que siga (o no) aumentando el acceso de las mujeres en las minas.

Por lo tanto, se puede ver de qué manera los desafíos que se asignan las trabajadoras no son sino reflejo de una demanda por igualdad de género, que hacen propia, y que ciertamente nos habla de un sujeto que se plantea en pos, no de padecer de un lugar secundario en la jerarquía entre los sexos, sino más bien de revertir dicha desigualdad a partir de su propia experiencia laboral. Estos desafíos, entonces, contribuyen de manera significativa a la emergencia del deseo de ser actor en sus vidas, de apropiarse de los 
significados del ser mujer minera y en su sentido genérico. Pues, antes que nada, se distancian de aquellas nociones tradicionales del género, y poco a poco comienzan a surgir en ellas voces autónomas de aquellos roles.

\section{Juicios propios}

De este modo llegamos al último momento a destacar aquellos juicios emanados desde su reflexividad y crítica. Uno de estos juicios es dirigido contra la propia empresa Codelco, evidenciándose cierta decepción hacia la misma: "nadie ha venido y le ha dicho a mis compañeros lo importante que es el trabajo que nosotras estamos haciendo en la minería, no queremos trato especial, pero sí que le abran la mente a los viejos y le digan' oye, sabí que lo que ella está haciendo es importante, necesita tu apoyo' no, a ti te tiran no más y te vai a trabajar a la mina" (Trabajadora A). La misma lógica de acción se da en otra de las críticas aparecidas. Esta vez en rechazo al machismo, tanto en la empresa como en la sociedad: "depende cómo enfrente una mujer el machismo de un hombre. Si un hombre es machista hasta que tú le aceptái que es machista, y es como tú le demostrí tus capacidades. (...) uno enseña a los hombres a no ser machistas, no, si tú estái en la fila primero, y estamos saliendo a la misma hora y hacemos el mismo trabajo. Y el hueón feliz porque tú lo dejaste pasar primero. Entonces, claro, tú lo veí como un tema de caballerosidad, pero esa cuestión de 'oye, es mina, hay que dejarla pasar', también los así machistas, porque somos iguales, estamos a la par, estamos haciendo lo mismo, cachái" (Trabajadora C). Resulta evidente que el sentimiento de desprotección entre las trabajadoras se manifiesta en sus dramas, como también la estigmatización de género en sus desafíos por demostrar igualdad. No obstante, esos dramas y desafíos los transforman en cuestionamiento y crítica (en este caso hacia la empresa y hacia el machismo), entonces las trabajadoras empiezan a tomar mayor control de su experiencia. De ahí que se abra paso a la producción de un contenido normativo propio. 
Pero no solo desde la crítica el actor se puede convertir en sujeto. También pudimos ver de qué modo algunas de las trabajadoras vislumbran posibilidades de cambio al machismo que enfrentan día a día. Así lo expresa una de las trabajadoras: "espero que algún día cambie totalmente esa mentalidad, que ya no hayan diferencias, ni la más mínima, de que tengái que demostrar, como te decía yo, tener que demostrar, que ser mujer itení que esforzarse el doble más? no po. (...) parte por uno también, si cada uno pensara así sería diferente y el criar a nuestros hijos con una mentalidad que no haga diferencias entre un hombre y una mujer. Sí se puede cambiar" (Trabajadora D). La proyección que acá se otorga a la experiencia se hizo notar en diversas trabajadoras, bajo la convicción de que el modo como ellas se desenvuelvan, tanto en su experiencia familiar como laboral, será fundamental para aportar a que se vaya eliminando el machismo de la sociedad. Por consiguiente, varias trabajadoras asumen en sus manos $-\mathrm{y}$ en ruptura con el orden patriarcal- la producción de valores culturales desde los ámbitos por donde ellas, individualmente, puedan influir. Solo la Trabajadora B tendrá intenciones de propiciar la acción colectiva en pos de posibilitar cambios desde su propia realidad laboral: "tengo una idea loca, y hablaba con otra chiquilla que a veces igual nos topamos en los turnos, de abrir un sindicato de mujeres, de trabajadoras de El Teniente. Sí, a mí me gustaría bastante, porque estas mismas cosas que te he dicho yo a ti, de las igualdades, podríamos abrir un sindicato de mujeres y hacer valer nuestros derechos como trabajadoras, tal igual como los hombres" (Trabajadora B). Queda en evidencia, a través de este caso particular, el potencial político en los procesos de subjetivación de género, como también el carácter colectivo que le podría otorgar a la acción y a la noción de sujeto.

\section{Reflexiones finales}

Como vimos, la experiencia laboral a la que se ven enfrentadas las mujeres mineras de la división El Teniente no se limita a meras vivencias. Dubet nos indica que "la experiencia social 
no es una 'esponja', una forma de incorporar el mundo a través de las emociones y de las sensaciones, sino una manera de construir el mundo. Es una actividad que estructura el carácter fluido de la vida" (Dubet, 2010, p. 86), que, en el ámbito del trabajo, a estas trabajadoras les significa ser capaces de administrar diversas lógicas de acción que no se reducen entre ellas y-lo que nos parece más interesante- que implica considerarlas desde su subjetividad.

Diremos entonces que la experiencia laboral de las trabajadoras de Codelco configura sus procesos de subjetivación de género, en la medida en que representa un desafío y un drama que asumen y enfrentan desde sus propios proyectos de vida, bajo la forma de un proyecto ético por la igualdad de género (en el trabajo y en la sociedad). Dicha idea la podemos asociar con el problema de la construcción de la sexualidad, pues "al adoptar una visión dinámica de la organización de la práctica, llegamos a una comprensión de la masculinidad y de la feminidad como proyectos de género. Estos son procesos de configuración de la práctica a través del tiempo" (Connel, 1995, p. 7). Ello se liga bastante a que, justamente, son las trabajadoras quienes experimentan y producen lo social por medio de sus críticas y afirmaciones frente a los valores y normas culturales de género. Por ende, pudimos observar un fenómeno de inserción laboral que, sin duda, va configurando las prácticas y estructurando los procesos de subjetivación en tanto proyectos de género, como bien lo muestra el caso femenino. Así, la mayoría de las trabajadoras no solo toman una distancia clara respecto de la posición subordinada que ocupa la mujer en el sistema de género, sino que, a su vez, se hacen cargo de construir una acción propia. Esta se ve representada, por ejemplo, en que su decisión de trabajar en la minería y de mantenerse (a pesar de los dramas y tensiones que viven), no solo responde a motivos económicos (que, por cierto, no dejan de ser los fundamentales), sino que también a razones de orden ético y moral: de asumir aquel desafío y, por tanto, poder demostrar la igualdad en el propio trabajo. 
Ahora bien, esta demanda por igualdad se puede interpretar desde una lógica de integración, sobre todo cuando se plantea únicamente en términos de capacidades en el trabajo. Es ese el caso de la Trabajadora F. Sin embargo, "el discurso de la comunidad y del orden moral puede también convertirse en el de la liberación desde el momento en que permite definir un sujeto y los obstáculos que se oponen a su formación" (Dubet, 2010, p. 119), como ocurre en la apropiación que la mayoría de las trabajadoras -no sin tensiones- hacen respecto de la igualdad de oportunidades promovida por la empresa, en tanto punto de inflexión que hace en ellas posible el surgimiento de la crítica (tanto hacia la empresa, como hacia el machismo en general). Asimismo, es la propia perspectiva elegida por las trabajadoras operarias y su interpretación de los valores, lo que nos permite plantear que estamos ante la emergencia de procesos de autodefinición cultural en estos sujetos.

Cabe señalar que si hablamos de una emergencia de los procesos de subjetivación es debido a que los observamos en pleno desarrollo (atendiendo, a su vez, al corto tiempo que llevan en la mina, el cual fluctúa entre los seis meses y tres años) y, por lo tanto, con rasgos disímiles. De ahí, por ejemplo, que tengamos casos como los de la Trabajadora C y la Trabajadora E, que si bien atraviesan procesos de subjetivación, afirman la igualdad desde una ambigüedad en torno a sus identidades de género. Esto se deja de manifiesto en la tensión que experimentan entre elementos de masculinización en sus identidades (como el caso de C) y de resistencia a estos desde la exacerbación del género femenino por sobre el masculino (como el caso de E). Dicho de otro modo, estos ejemplos nos permiten observar que la disputa que surge de los procesos de subjetivación de género, respecto de los significados del ser mujer trabajadora (en la minería y en la sociedad), se nutren de interpretaciones heterogéneas, razón por la cual el proyecto ético por la igualdad aún se presenta de un modo difuso y a ratos contradictorio. En tanto, los casos de A, B y D se muestran en un nivel intermedio frente a esta tensión, otorgándole mayor consistencia a la crítica y afirmación de las trabajadoras frente al orden de género. 
A modo de síntesis, diremos que el imperativo ético que opera como catalizador de la reflexividad implica, para la mayoría de las entrevistadas, un deseo de ser autoras de sus vidas en tanto mujeres trabajadoras (deseo que se expresa desde un autor aún individual, pero donde afloran casos como la Trabajadora B, en la que se observa el deseo de ser actor colectivo). Por lo mismo, el hecho de que las relaciones sociales se presenten "en términos de obstáculos para el reconocimiento y para la expresión de esta subjetivación" (Dubet, 2010, p. 117), se enfrenta en casi todos los casos desde la necesidad de la superación constante, de vencerle a la vida, de demostrar que la mujer puede tanto o más de lo que las expectativas sociales le conceden, e incluso en términos de posibilidades de transformación de la realidad y de asumir un rol propio, por el cual no solo se ve atravesada su experiencia laboral, sino también aspectos de su experiencia familiar.

Podemos señalar, entonces, que el "hito Sernam-Codelco" generó una ampliación en la división sexual del trabajo, la cual, leída desde la perspectiva de la subjetividad de las trabajadoras, representa una emergente ruptura con el "Yo social" femenino, que asumen desde el imperativo de la "reconstrucción de una cierta dignidad, de un Yo propio, independiente de las categorías de identidad impuestas desde fuera" (Dubet, 2010, p. 90). Ello demuestra que los procesos de subjetivación de género en las trabajadoras de El Teniente se estructuran antes desde el rechazo a las categorías generales -si se quiere patriarcales- de las relaciones sociales entre los sexos -y que experimentan en sus relaciones laborales-, que desde la distancia respecto del rol que las empresas mineras (y en particular Codelco) les atribuyen. Pues este último rol no viene a ser, para las trabajadoras, más que un fundamento distintivo desde el cual logran integrarse $y$, a partir de un apoyo mínimo de dicha integración, aplicar las estrategias necesarias para ser legitimadas y valoradas como trabajadoras mineras. De ahí entonces que, indirectamente y desde otro punto de vista a esos roles e intereses, aparezca la lógica del sujeto. 


\section{Bibliografía}

Aguiar, S. (2007). Evidencias sobre participación laboral femenina. Mercado de trabajo especifico y relaciones de producción. En: Cuadernos de Estudios del Trabajo No 2, Estudios del Trabajo. Chile.

Angelcos, N. (2008). Subjetividad y política. Sobre el rendimiento sociológico de los procesos de subjetivación. Tesis para optar al título de sociólogo, Universidad de Chile.

Astelarra, J. (2003). ¿Libres e iguales? Sociedad y política desde el feminismo. Santiago. CEM.

Bourdieu, P. (2007). La dominación masculina. Barcelona: Anagrama.

Carosio, A. (2012). Mujeres hacia el socialismo en Venezuela. En: Carosio (Coord.). Feminismo y cambio social en América Latina y el Caribe. (pp. 101-136). Buenos Aires, Argentina: CLACSO.

Castel, R. (2010). El ascenso de las incertidumbres: trabajo, protecciones, estatuto del individuo. Buenos Aires, Argentina: Fondo de Cultura Económica.

Cerda, C. \& Cuevas, H. (sin año). Mujer, Trabajo y Sindicalismo. Más allá del feminismo. En: Solidaridad Hoy. En línea.

Connel, R. (1995). The social organization of masculinity. Berkeley: University of California Press.

Consejo Minero (2012). Fuerza laboral de la gran minería chilena 20122020. Diagnóstico y recomendaciones. Iniciativa del Consejo de Competencias Mineras (CCM). Elaborado por Innovum, Fundación Chile.

Dubet, F. y Martuccelli, D. (2000). ¿En qué sociedad vivimos? Buenos Aires, Argentina: Losada.

Dubet, F. (2010). La sociología de la experiencia. Madrid: Editorial Complutense.

Espinoza, M. \& Morris, P. (2001). Hacia una agenda sindical de género en el Mercosur. En: Seminario Regional Mercosur. Inserción laboral de la mujer en los países del Mercosur y Chile". Análisis Laboral $N^{\circ} 15$, Santiago, Chile.

Fridan, B. (1981). The Second Stage: With a New Introduction. Edición reimpresa, Harvard University Press.

Girón, A. (2012). Feminismo. Quiebres y zurcidos en crisis. En: Carosio (Coord.). Feminismo y cambio social en América Latina y El Caribe. (pp. 43-56) Buenos Aires, Argentina: CLACSO. 
Izquierdo, M.J. (2004). Del sexismo y la mercantilización del cuidado a su socialización: hacia una política democrática del cuidado. En: Rincón, Ana (Coord.). Congreso Internacional Sare 2003. Cuidar cuesta: costes y beneficios del cuidado (pp. 119154). Edición Emakunde/Instituto Vasco de la Mujer. Comunidad Europea.

Klubock, T. (1992). Sexualidad y proletarización en la mina El Teniente. En Proposiciones Vol.21. Santiago de Chile: Ediciones Sur.

Madoo, P. y Niebrugge-Brantley, J. (1993). Teoría feminista contemporánea. En Ritzer, G. Teoría sociológica contemporánea (pp. 353409). España: McGraw Hill.

Pavéz, J. y Hernández, G. (2014). Regímenes de trabajo, relaciones laborales y masculinidades en la gran minería del cobre (norte de Chile). En X. Valdés, L. Rebolledo, J. Pavéz y G. Hernández, Trabajos y familias en el neoliberalismo. Hombres y mujeres en faenas de la uva, el salmón y el cobre (pp. 169-263). LOM: Santiago.

Pérez, P. (2009). El mercado laboral chileno y sus transformaciones durante los últimos 20 años. ¿Hacia una reconfiguración de la estructura de clases en Chile? Artículo no publicado.

Ridgeway, C. (2011). Framed by gender. How gender inequality persists in the modern world. New York: Oxford University Press.

Salinas, P., Barrientos, J. y Rojas, P. (2012). Discursos sobre la discriminación de género en los trabajadores mineros del norte de Chile. Revista Atenea, 505, 139-57.

Servicio Nacional de la Mujer (SERNAM). (2011). Mensaje Presidencial. En línea.

Sepúlveda, L. (2009). “Políticas para la inserción laboral de mujeres y jóvenes en Chile". Colección Documento de proyectos, CEPAL. En línea.

Tapia, Z. (2011). Chile: La mujer en la minería y en la prevención de conflictos mineros. En: Taller internacional. Inclusión del enfoque de género en la prevención de conflictos mineros. Araníbar, Ana María (Coord.). CYTED, GECOMIN, COMIBOL, OLAMI. La Paz, Bolivia.

Touraine, A. (2000). Crítica de la Modernidad. México: Fondo de Cultura Económica. 


\section{Artículos de prensa:}

Codelco (2011). Codelco se compromete a incorporar más mujeres a su dotación (30 de septiembre). Recuperado el 5 de Octubre 2013, de http://www.codelco.com/codelco-se-compromete-a-incorporar-mas-mujeres-a-su-dotacion/prontus_ codelco/2011-09-30/173057.html

Codelco (2013). Fuerte aumento de las mujeres entre trabajadores, profesionales y ejecutivos de Codelco (7 de marzo). Recuperado el 13 de Octubre 2013, de http:/ / www.codelco.com/fuerte-aumento-de-las-mujeres-entre-trabajadores-profesionales-y-ejecutivos-de-codelco/prontus_codelco/2013-03-07/170615. html. 